\title{
Relative Importance of Intellectual Capital Determinants, Using an Artificial Neural Network Approach: Case Study - Mellat Bank of Iran
}

\section{Mona Safarnejad Shad ${ }^{1 *}$, Arman Nedjati ${ }^{2}$ and Mohsen Shafiei ${ }^{1}$}

${ }^{1}$ Department of Economy and Management, Semnan University, Semnan, Iran

${ }^{2}$ Industrial Engineering Department, Islamic Azad University (Branch of Lahijan), Lahijan, Iran

\begin{abstract}
Intellectual capital (IC) is the main part of intangible assets and provides competitive advantages for organizations. Therefore, evaluating these assets has a significant value for companies. The aim of this study is to determine the relative importance of IC determinants. Two kinds of questionnaires related to IC were used to collect data for Artificial Neural Network (ANN) and Analytic Hierarchy Process (AHP) methods. In the next step the accuracy of ANN is compared with Multiple Linear Regression and Nonlinear Least Square Fitting methods. Factor analysis is also applied to validate the model and reduction of indicators. Finally, to gain assurance about the ANN results, the results are compared with the AHP's outcome. The obtained importance order of three IC determinants in the studied banking system is relational capital, human capital and structural capital respectively.
\end{abstract}

Keywords: Intellectual capital; Artificial neural network; Relative importance; Analytical hierarchy process; Nonlinear least square fitting

\section{Introduction}

By the growth of the modern economy, that is primarily powered by knowledge and information, is credited towards the improved dominance of intellectual capital (IC) as an investigation subject [1]. Drucker was pioneered in appearance of a novel economy, known as the knowledge contemporary society [2]. He states that in this modern society, knowledge is not only an additional source together with the conventional aspects of production (land, labor, and capital) however it is typically the solely significant resource for manufacturing [3]. In the last decade, there is a more focus on the knowledge participation in global competitiveness in 21st century. Knowledge is known as an indelible strategic resource to gain and sustain reasonably competitive benefits [4,5]. Since IC is based on knowledge, it is the central part of organizational capabilities. The necessity of improvement and upgrading this knowledge has never been focused. Core competencies represent organizational excellence scopes, which are resulted from capabilities combinations [6].

In recent century, IC has become the main asset of large international companies. Tangible properties include physical property (machines, land, and buildings) and current property (inventory). The other category comprises intangible properties: individuals as well as their skills, business procedures and market assets including customer loyalty, recurring business reputation, and so on [7]. Most often Intangible assets were defined very narrowly, and didn't consist of assets including human resources, client loyalty, and organization reputation. However, these components of IC, if managed properly, have a great value creation potential which no longer companies concluded they shouldn't ignore it [8].

The basic idea that a great value is embedded in organizations, beyond their physical assets, has been considered for years. Tobin's $\mathrm{q}$ formula mentions IC is the scale of the gap between a firm's value and the substitute expense of its physical properties [9]. A general agreement says that "intangibles" could be divided in several unique types of nonfinancial assets [10]. Edvinsson [11] describe that IC progressively offers the bases of a corporation's value, being the hidden elements that contribute to generate it in the organization, in addition to the share of physical assets. Brooking confirms the concept [12], and claims that it is essential to offer valuations associate with shares of intangible properties, since administrators require to spot their company's most precious resources. Furthermore, focusing on how much important these assets are, it is valuable to determine the intangible assets' status in value creation procedure. When generating value, competitive advantage is accomplished with the ideal use of intangibles [13]. Whenever a company's administration is not conscious of what its intangible properties are, it could miss beneficial opportunities depending on these intangible capitals, since key decisions will made without considering all possible variables [14].

The main aim of this paper is identifying and quantifying the relative importance of various IC determinants in Mellat Bank of Iran. The ANN and Hierarchy Process (AHP) methods are used to determine and quantify the three main determinants of the IC. The ANN results are compared with direct evaluating of human by AHP. Many scholars have examined categorization models for projects selection and evaluation by Analytic Hierarchy Process method [1521] and Mehralian et al. [22], used fuzzy TOPSIS for Prioritization of IC indicators; But innovation of this research is evaluating the relative importance of IC factors by ANN.

\section{Intellectual capital background}

By a close review of Intellectual Capital literature, it is observed that all existing models of IC evaluation are identified three similar determinants for IC [23]. Based on some pioneers opinion IC is composed of three main components [11,24-28]:

\section{- $\quad$ Structural capital,}

*Corresponding author: Arman Nedjati, Industrial Engineering Department Islamic Azad University (Branch of Lahijan), Lahijan, Iran, Tel: +989114751320; E-mail: arman.nedjati@gmail.com

Received August 24, 2017; Accepted August 30, 2017; Published September 06, 2017

Citation: Shad MS, Nedjati A, Shafiei M (2017) Relative Importance of Intellectual Capital Determinants, Using an Artificial Neural Network Approach: Case Study Mellat Bank of Iran. J Bus Fin Aff 6: 285. doi: 10.4172/2167-0234.1000285

Copyright: ( 2017 Shad MS, et al. This is an open-access article distributed under the terms of the Creative Commons Attribution License, which permits unrestricted use, distribution, and reproduction in any medium, provided the original author and source are credited. 
- $\quad$ Customer capital, and

- Relational capital.

Also this categorization has been used in the literature of recent studies [29-31].

Stewart [27] stated IC is not the mathematical integration of capabilities and knowledge which could create wealth and value, however as Brooking, Marr et al., Roos and Roos explain, it is the organizational capital that includes infrastructure, organizational relationships, culture, other management processes, and intellectual capital $[12,32,33]$.

The human capital: Human capital is the knowledge inventory of humans in a company which is embedded in its individuals [13]. As a result, one can say human capital is composed of employees' knowledge, skills, capabilities, etc., that are used or probably could be used to generate organizational value [34]. Human capital has a critical role in creating innovation, which would result from a reengineering new process, emitting old files, improving personal skills, daydreaming at the office, or brainstorming in a research lab [35].

Roos [36] stated IC is created by employees' competencies, attitudes and intellectual agility. Bontis [37] explains human capital as organizational collective capability resulted from its employee's knowledge aggregation to gain the best answers. Although employees have critical role in learning organizations, but they are not belonging to the organization as its skilled member assets. Some studies have discussed about this common knowledge capital's debate, whether provided innovation, creativity and knowledge by employees (such as written codes by a programmer at home that might be useful for specified company) is under organizational ownership or not. Human capital is all organizational embedded tacit knowledge [38].

The structural capital: Organizations create Structural capital as an infrastructure to commercialize the intangible capitals [39]. Structural capital is accompanied by technological and organizational factors to promote organizational coordination and integration. Structural capital is organizational capabilities, organizational culture, databases, software, hardware, and trademarks of organization [11,33]. Roos et al. [40] define structural capital as "what remains in the company when employees go home for the night". Structural capital resulted from processes and organizational value and presents external and internal aspects of the organizations, and its development and renewal value. Structural capital includes all knowledge storage of the organizations such as routines, strategies, process manuals, charts, databases, and anything whose incorporeal value is greater than its physical value [41]. Also, structural capital is divided process capital and innovation capital. Innovation capital is an explicit, integrate result of innovation in the form of protected commercial rights, intellectual property and other intangible resources and values, and process capital is "the combined value of value-creating and non-value-creating process" [11]. IC could measure and promote in organizations by structural capital concept. So, without structural capital, IC would be only a human capital [37]. Structural capital is supportive infrastructure of human capital and Embedded in organizations [35]. It contains different elements such as technology transfer, process effectiveness, information systems and IT satisfaction. Structural capital is a critical concept which facilitates measuring IC in organizations [37]. So organizational capital is critical element of organizations, and is a key factor in measuring organizational IC [42].

The customer capital: Customer capital is composed of customer relationship and brand value. Cañibano et al. and Bontis recalled customer capital as relational capital because it should include organization's interactions with its clients and with any other related parties $[13,43]$.

In the unique model of Edvinsson [11], relational capital was embedded under structural capital concept. However, Bozbura [44] mentioned that relational capital and customer capital are to distinct concepts. He believes that relational capital could be the sum of all properties that organize and control the company's relationships with the environment. The relational capital contains the relationships with society, official institutions, community, shareholders, suppliers, and customers. Customer capital is both the present value of a company's relation with its customers and the possible future worth of these relationships [45]. It includes embedded knowledge in organizational relationships with suppliers, stockholders, strategic alliance partners, customers, etc. [37].

\section{Methodology}

\section{Intellectual capital internal factors}

Most of the researchers agree to broken down ICs or intangible assets in a number of different defined nonfinancial capitals. However, we may have different names but most researchers divide IC into three concepts: human capital, customer (relational) capital and structural (organization) capital. In this study, each of these factors were define clearly using literature review. Increasing employees' capabilities has a great impact on financial outcomes of the organization [46]. For these reasons, it can be claimed that, the human capital has a direct relationship with organizational performance [44]. And also better identification of customers' requirements about a product or a service compared to anybody else is what makes one a business director, in contrast to a follower [37]. Customer capital signifies organizational potentials resulted from its external intangibles [47]. After all, based on structural capital the company will have strong innovative culture, learning system and information system.

The research model is shown in Figure 1, proposed based on literature review and expert's opinions, and hypothesized the relationship between these factors as follow:

H1: Considering Human capital's relation with other two factors, it has a significant and positive relation with IC,

H2: Considering Structural capital's relation with other two factors, it has a significant and positive relation with IC,

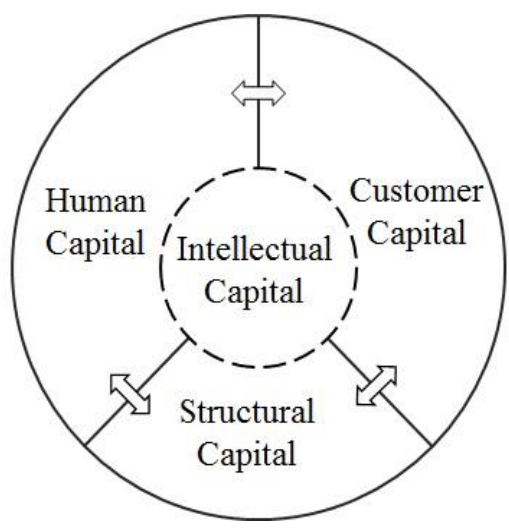

Figure 1: The model of hypothesizes. 
H3: Considering Customer capital's relation with other two factors, it has a significant and positive relation with IC.

\section{Artificial neural networks}

Artificial Neural Networks (ANNs) method is utilized as a great method in engineering and management area particularly in computer sciences. The primary sign of the neural networks is a flexible, paralleldistributed and non-algorithmic memory [48]. Neural networks are patterned by inspiring from biological neural system with an uncomplicated framework. ANNs are used widely to unknown models or unknown functional relationships between the input and output of a process or system. ANN provides strong decision support and enables modeling complex systems with nonlinear relationships. ANN begins by allocating arbitrary weights to the variables and then modifying these weights in a feed-forward, back propagation style to minimize the difference between the real and expected outputs. The neurons exist in the hidden layer move the weighted input data toward the output utilizing nonlinear transfer functions [49]. Figure 2 provides a sample three layer ANN model with $\mathrm{N}$ units in input layer and $\mathrm{P}$ hidden units by logistic functions in the middle layer and $\mathrm{M}$ output identity function in output unit.

Collected data by IC questionnaire [37], were used for ANN training. Indicators of IC and value of IC, respectively are Input and output value for ANN. Tenfold cross validation process was used for train and test process. For determining the relative importance of each input to the output several studies have performed [50-52]. Accuracy of ANN is compared with Multiple Linear Regression (MLR) and Nonlinear Least Square Fitting (NLSF) methods. To gain assurance about ANN result, it is benchmarked with expert idea about IC, through AHP. Generally we follow the approach presented by Wong et al. [53].

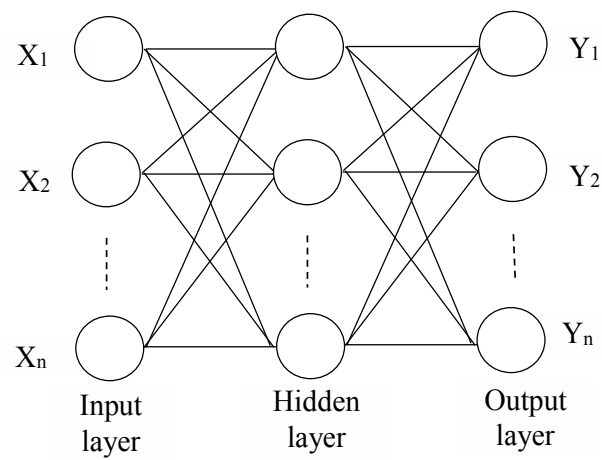

Figure 2: The ANN with $\mathrm{N}$ input, $\mathrm{P}$ hidden and $\mathrm{M}$ output neurons.

\section{Case Study}

\section{Background}

Nowadays in most of researches which are based on data collecting from samples by observation or questionnaire, data analysis plays a very important role in study. In design and analysis of experiments of this study, first descriptive statistics is used for scrutiny of sociological variables like gender, education, age and etc., and then statistics analysis performs. Pearson correlation test is used for specifying the relation of three main factors (Human Capital, Costumer Capital and Structural Capital) with IC. Also confirmatory factorial analysis is used to identify the most important indicators of IC in our case study. ANN is utilized to determine the relative importance of three IC factors. However, we used linear and nonlinear methods to be assured of ANN results, but also the results are compared with real human based results of AHP.

The populations of this study are branches of Mellat Bank of Iran, and partners are the employees with at least 5 years old experience or having at least bachelor degree in economy or management, the researchers with interest areas related to IC or managers who are responsible for evaluating of intellectual property in each branch. Two different questionnaires are used, the first one is standard questionnaire of IC for all the participants [37], and the second one is prepared questionnaire for AHP that were answered by Bank employees with more than 10 and even 15 years old experience and academic professors of University. Factor analysis is used to reduce the amount of factors for AHP questionnaire.

\section{Findings}

Distribution of sample was studied by descriptive statistics analysis based on variables like gender, age, education, position and job experience; the results are shown in Figure 3.

\section{Hypothesizes and Pearson correlation coefficient calculating}

According to Table $1 \mathrm{H} 1, \mathrm{H} 2$ and $\mathrm{H} 3$ are accepted. So human capital (X1), customer capital (X2), and structural capital (X3) have significantly correlation with IC (Y). And because the correlation coefficient between these pairs are positive so it can be eventuated that structural capital, human capital and customer capital have positive correlation with IC, it means If the value of $\mathrm{X} 1, \mathrm{X} 2$, and $\mathrm{X} 3$ are increased, then $\mathrm{Y}$ increases as well.

\section{Confirmatory factor analysis}

Factor analysis is used to reduce the number of indicators for identifying the most important ones. By using LISREL 8.5 software, first step and second step factor analysis are done. Thirty IC indicators

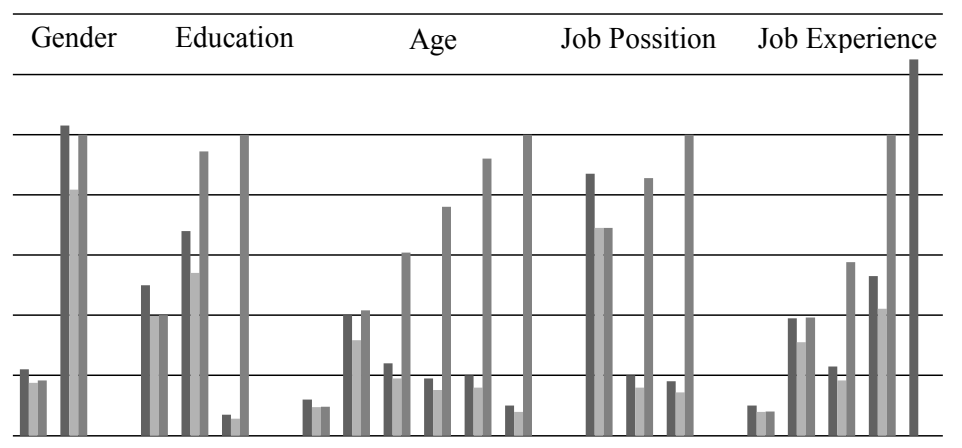

- Frequency

Frequency percentage

- Cumulative frecuency percentage 
Citation: Shad MS, Nedjati A, Shafiei M (2017) Relative Importance of Intellectual Capital Determinants, Using an Artificial Neural Network Approach: Case Study - Mellat Bank of Iran. J Bus Fin Aff 6: 285. doi: 10.4172/2167-0234.1000285

Page 4 of 9

\begin{tabular}{|c|c|c|c|}
\hline Variable name & Human Capital & Customer Capital \\
\hline Correlation & 0.674 & 0.678 \\
\hline Sig & 0.01 & 0.01 \\
\hline Path & $\mathrm{X}_{1} \leftrightarrow \mathrm{Y}$ & $\mathrm{X}_{2} \leftrightarrow \mathrm{Y}$ & 0.01 \\
\hline Result & $\mathrm{H}$ : Supported & $\mathrm{H}$ 2: Supported \\
\hline
\end{tabular}

Table 1: Results of hypothesizes testing

with less than 0.4 factor loadings are eliminated, and after model adjustment, the second step factor analysis with remaining indicators is done. The number of IC indicators decreased from 53 to 23 ones. The results are shown in Table 2.

\section{Architectural design and assessment accuracy of the ANN model}

ANN approach is the main method for calculation of relative importance (of every input to single output) in this study. To do this, first the artificial neural networks architecture is designed, then for assessing accuracy of ANN the results are compared with multiple linear regressions (MLR) and nonlinear least square fitting (NLFS) methods. Inputs of ANN are indicators (predictors) and actual value of IC (Target). Target is produced from predictors. Transfer function for hidden and output layer, respectively is tansing and purlin.

\section{Selecting the best ANN model}

Total gathered samples are 125. According to tenfold cross validation $90 \%$ of them $(=113)$ is assigned to the train set, and $10 \%$ $(\mathrm{K}=12)$ of them is assigned to the test set $[52,53]$.

Three types of ANN are trained with 10 fold cross validation:

- Type one with 53 inputs includes all indicators of IC.

- $\quad$ Type two with 23 inputs includes indicators remain after factor analysis with factors loadings more than 0.4.

- $\quad$ Type three with 8 input included indicators remain after factor analysis with factors loadings more than 0.55 .

To find appropriate and reliable ANN model, those with different number of inputs and neurons are trained and train process is repeated for 10 times and the results are shown in Table 3. The model precision was calculated by the average and minimum MAPE, average Pearson correlation (R), standard deviation (SD), and the average mean absolute percentage error (MAPE) over 10 fold of cross validations. The trial and error is applied in order to find the value of $\mathrm{P}$.

ANN with lowest MAPE and SD, and biggest $\mathrm{R}$ is the best [54]. So ANN Type two with neuron=3, MAPE=9.18, $\mathrm{SD}=2.99, \mathrm{R}=0.57$, MIN=4.99 (minimum of MAPE) which is shown bold in the Table 3 is the best model in comparison with others for our case.

After this session the training process is ran for ten times to find the possible minimum of MAPE. The results with error of each test data set over ten-fold cross validation are mentioned in Table 4. E1 represents the prediction error of ANN through first fold data set, E2 refers to the prediction error of ANN through second fold data set and etc., and MAPE is the mean absolute percentage error over 10 data set in cross validation. It is noticed that lowest error of the ANN is $2.01 \%$. To be able to measure the accuracy of ANN, it is reconciled with MLR and NLSF.

\section{Multiple linear regressions (MLR)}

Multiple linear regression model is the main tool for calculating the

\begin{tabular}{|c|c|c|c|}
\hline Indicators & & $\begin{array}{l}\text { Factor } \\
\text { loading }\end{array}$ & Result \\
\hline \multicolumn{4}{|c|}{ Human capital } \\
\hline $\mathrm{H} 1$ & Competence ideal level & 0.2 & Rejected \\
\hline $\mathrm{H} 2$ & Succession training program & -0.22 & Rejected \\
\hline $\mathrm{H} 3$ & Planners on schedule & 0.35 & Rejected \\
\hline $\mathrm{H} 4$ & Employees cooperate in teams & 0.34 & Rejected \\
\hline H5R & Work groups relationship & 0.51 & Accepted \\
\hline $\mathrm{H} 6$ & Come up with new ideas & 0.43 & Accepted \\
\hline $\mathrm{H} 7$ & Upgrade employees' skills & 0.64 & Accepted \\
\hline $\mathrm{H} 8$ & Employees are bright & 0.47 & Accepted \\
\hline $\mathrm{H} 9$ & Employees are best in industry & 0.33 & Rejected \\
\hline $\mathrm{H} 10$ & Employees are satisfied & 0.48 & Accepted \\
\hline $\mathrm{H} 11$ & Employees perform their best & 0.21 & Rejected \\
\hline $\mathrm{H} 12$ & $\begin{array}{l}\text { Recruitment program } \\
\text { comprehensive }\end{array}$ & 0.38 & Accepted \\
\hline H13 R & Big trouble if individuals left & -0.13 & Rejected \\
\hline H14 R & Rarely think actions through & -0.13 & Rejected \\
\hline H15 R & Do without thinking & 0.12 & Accepted \\
\hline $\mathrm{H} 16$ & Individuals learn from others & 0.09 & Rejected \\
\hline $\mathrm{H} 17$ & Employees voice opinions & 0.52 & Accepted \\
\hline $\mathrm{H} 18$ & Get the most out of employees & 0.32 & Rejected \\
\hline H19 R & Bring down to others' level & -0.40 & Rejected \\
\hline $\mathrm{H} 20$ & Employees give it their all & 0.32 & Rejected \\
\hline \multicolumn{4}{|c|}{ Customer Capital } \\
\hline C1 & Customers generally satisfied & 0.37 & Rejected \\
\hline $\mathrm{C} 2$ & Reduce time to resolve problem & 0.20 & Rejected \\
\hline $\mathrm{C} 3$ & Market share improving & 0.30 & Rejected \\
\hline C4 & Market share is highest & 0.39 & Rejected \\
\hline C5 & Longevity of relationships & 0.43 & Accepted \\
\hline C6 & Value added service & 0.62 & Accepted \\
\hline $\mathrm{C} 7$ & Customers are loyal & 0.54 & Accepted \\
\hline $\mathrm{C} 8$ & Customers increasingly select us & 0.50 & Accepted \\
\hline C9 & Firm is market-oriented & 0.43 & Accepted \\
\hline C10 & Meet with customers & 0.55 & Accepted \\
\hline C11 & Customer info disseminated & 0.50 & Accepted \\
\hline C12 & Understand target markets & 0.45 & Accepted \\
\hline C13R & Do not care what customer wants & -0.33 & Rejected \\
\hline C14 & Capitalize on customers' wants & 0.54 & Accepted \\
\hline C15R & Launch what customers don't want & -0.14 & Rejected \\
\hline C16 & Confident of future with customer & 0.39 & Rejected \\
\hline C17 & Customer feedback & 0.50 & Accepted \\
\hline \multicolumn{4}{|c|}{ Structural Capital } \\
\hline S1 & Lowest cost per transaction & 0.27 & Rejected \\
\hline $\mathrm{S} 2$ & Improving cost per revenue $\$$ & 0.21 & Rejected \\
\hline S3 & Increase revenue per employee & 0.24 & Rejected \\
\hline S4 & New idea perform & 0.51 & Accepted \\
\hline S5 & Transaction time decreasing & 0.19 & Rejected \\
\hline S6 & Transaction time is best & 0.39 & Rejected \\
\hline S7 & Capitation revenue & 0.41 & Accepted \\
\hline S8 & Innovation support & 0.58 & Accepted \\
\hline S9 & Develops most ideas in industry & 0.38 & Rejected \\
\hline $\mathrm{S} 10$ & Investment efficiency & 0.48 & Accepted \\
\hline $\mathrm{S} 11$ & Information availability & 0.47 & Accepted \\
\hline $\mathrm{S} 12$ & Organizational system simplify & 0.61 & Accepted \\
\hline S13 & Bureaucracy & 0.41 & Accepted \\
\hline S14 & Cooperation system & 0.55 & Accepted \\
\hline S15 & Organizational culture & 0.46 & Accepted \\
\hline S16R & Do not share knowledge & -0.07 & Rejected \\
\hline
\end{tabular}

Table 2: Final IC indicators (main terms of questionnaire). 
relative importance in wide scientific fields. This method is also called "multiple linear regressions with non-zero intercept". The general form of linear regression is

$$
Y=\beta X+\varepsilon
$$

That $\beta$ is the unknown coefficient variables matrix, $\mathrm{X}$ is the known observed variables matrix, and $\varepsilon$ is the residuals between observed $(\mathrm{Y})$ and predicted $(\hat{Y})$ IC value. This study's model equation is

$$
Y(X i \mid \beta)=\beta_{1}+\beta_{2} X_{1}+\beta_{3} X_{1} X_{2}+\beta_{4} X_{1} X_{3}+\beta_{5} X_{2} X_{3}+\beta_{6} X_{1} X_{2} X_{3}+\varepsilon
$$

In this model $\mathrm{X}_{1}, \mathrm{X}_{2}$ and $\mathrm{X}_{3}$ are internal factors of customer capital, human capital, and structural capital, and $\beta$ is the correlation coefficient of them. MLR mechanism is used to minimize the sum of squared residuals of this model by predicted $\hat{\beta}$ as;

$$
\hat{\beta}=\left(X^{T} X\right)^{-1} X^{T} Y
$$

In order to calculating $\mathrm{X}_{\mathrm{i}}$ for three main IC factors the questionnaire

\begin{tabular}{|c|c|c|c|c|c|}
\hline Neuron no. & $\begin{array}{l}\text { Model } \\
\text { Type }\end{array}$ & MAPE & SD & $\mathbf{R}$ & MIN \\
\hline \multirow[t]{3}{*}{$P=3$} & 1 & 10.2 & 4.08 & 0.49 & 5.17 \\
\hline & 2 & 9.18 & 2.99 & 0.57 & 4.99 \\
\hline & 3 & 10.82 & 3.31 & 0.43 & 6.4 \\
\hline \multirow[t]{3}{*}{$P=4$} & 1 & 9.78 & 3.77 & 0.55 & 4.32 \\
\hline & 2 & 10.3 & 3.38 & 0.55 & 4.63 \\
\hline & 3 & 10.81 & 3.26 & 0.45 & 6.74 \\
\hline \multirow[t]{3}{*}{$P=5$} & 1 & 10.9 & 3.95 & 0.52 & 5.79 \\
\hline & 2 & 10.5 & 3.28 & 0.53 & 6.38 \\
\hline & 3 & 10.75 & 3.29 & 0.44 & 6.17 \\
\hline \multirow[t]{3}{*}{$P=6$} & 1 & 11.07 & 2.96 & 0.56 & 7.02 \\
\hline & 2 & 10.65 & 3.56 & 0.53 & 5.9 \\
\hline & 3 & 11.52 & 3.84 & 0.41 & 6.83 \\
\hline \multirow[t]{3}{*}{$P=7$} & 1 & 10.7 & 3.3 & 0.54 & 6.54 \\
\hline & 2 & 11.34 & 3.55 & 0.49 & 6.37 \\
\hline & 3 & 11.77 & 4.11 & 0.43 & 6.66 \\
\hline \multirow[t]{3}{*}{$P=8$} & 1 & 10.66 & 3.47 & 0.55 & 6.05 \\
\hline & 2 & 11.41 & 3.8 & 0.52 & 6.51 \\
\hline & 3 & 11.94 & 3.64 & 0.39 & 7.26 \\
\hline \multirow[t]{3}{*}{$P=9$} & 1 & 11.17 & 3.47 & 0.55 & 6.46 \\
\hline & 2 & 12.18 & 3.55 & 0.46 & 7.21 \\
\hline & 3 & 11.61 & 3.66 & 0.42 & 6.32 \\
\hline
\end{tabular}
results of 53 indicators are used, so the participants did not weight directly to the main factors.

Table 3: Cross-validation training results of ANN with varying inputs and neurons.

\section{Nonlinear least square fitting (NLSF) method}

NLSF is a kind of least squares analysis which is used to fit a set of $\mathrm{N}$ observations with $\mathrm{M}$ unknown parameters $(\mathrm{N}>\mathrm{M})$. The quantity of measurement $\mathrm{Y}$ is calculated by nonlinear function of eqn. 4 which contains $\mathrm{X}_{\mathrm{i}}$ variables and some unknown coefficients of $\beta$ parameters, so it is desired that the curve fits best the given data, but each $Y_{i}$ is corrupted by an error in terms $e_{i}$. The NLSF minimizes the sum of square of errors in order to find the best $\beta$ for model. The sum of square of errors is calculated as a chi-square distribution shown in Eq.5. The residuals are the difference between observed outputs $\left(\mathrm{Y}_{\mathrm{i}}\right)$ and estimated outputs $\left(\mathrm{Y}\left(\mathrm{X}_{\mathrm{i}} \mathrm{b}\right)\right)$ as defined in Eq.6. The estimated outputs are calculated with actual inputs $\left(\mathrm{X}_{\mathrm{i}}\right)$. MATLAB is a proper tool for finding the minimum sum of square of errors.

$$
\begin{aligned}
& Y_{i}=Y\left(X_{i} \mid b\right)+e_{i} \\
& \chi^{2}=\sum_{i}\left(\frac{y_{i}-y\left(X_{i} \mid b\right)}{\partial_{i}}\right)^{2} \\
& \frac{y_{i}-y\left(X_{i} \mid b\right)}{\partial_{i}}=Y_{i}-Y\left(X_{i} \mid b\right)
\end{aligned}
$$

A nonlinear function should be assumed; also coefficient " $b$ " must be guessed. Curve fitting tool in MATLAB (7.9.0) is used for this aim. Several nonlinear functions (e.g., Fourier, Power, exponential, Sum of Sin) have been used, finally "Sum of Sin" Function, presented the best fitting result. Therefore, Chosen nonlinear function is:

$$
\begin{aligned}
& y(X \mid b)=b_{1}+b_{2} \sin \left(b_{3} X\right)+b_{4} \sin \left(b_{5} X\right)+ \\
& b_{6} \sin \left(b_{7} X\right)+b_{8} \sin \left(b_{9} X\right)+b_{10} \sin \left(b_{11} X\right)+b_{12} \sin \left(b_{13} X\right)+ \\
& b_{14} \sin \left(b_{15} X\right)+b_{16} \sin \left(b_{17} X\right)
\end{aligned}
$$

In eqn.7 $\mathrm{y}$ is the predicted value that should be compared with responses and $\mathrm{X}$ is the predictor. Actually parameter $\mathrm{y}$ is a part of the function; therefore it should be extend for 23 variables.

\section{Comparison between ANN, MLR and NLSF}

After using this three prediction method, to estimate $\mathrm{Y}$ (actual value of IC), several advantages of ANN is became obvious. In input layer of ANN there is no limitation for number of inputs, in other word a matrix with $\mathrm{M}$ by $\mathrm{N}$ dimension exists, $\mathrm{M}$ is number of predictors (=23), and $\mathrm{N}$ is Number of observations $(=125)$. It is easily used for extracting hidden features of collected data. ANN is an intelligent tool for finding nonlinear function through data, and there is no need to find an appropriate function with trial-error method.

\begin{tabular}{|r|r|r|r|r|r|r|r|r|r|r|}
\hline Fold no. & $\mathbf{1}$ & $\mathbf{2}$ & $\mathbf{3}$ & $\mathbf{4}$ & $\mathbf{5}$ & $\mathbf{6}$ & $\mathbf{7}$ & $\mathbf{8}$ & $\mathbf{9}$ & $\mathbf{1 0}$ \\
\hline E1 & 3.54 & 0.61 & 0.10 & 0.22 & 5.24 & 13.09 & 3.44 & 28.60 & 0.05 & 10.45 \\
\hline E2 & 14.06 & 0.77 & 2.39 & 0.00 & 50.85 & 0.68 & 4.88 & 25.15 & 18.71 & 6.59 \\
\hline E3 & 0.76 & 0.61 & 0.32 & 0.00 & 3.08 & 0.68 & 20.71 & 0.05 & 1.96 \\
\hline E4 & 4.23 & 0.41 & 3.92 & 0.00 & 6.75 & 20.14 & 28.69 & 0.13 & 3.17 \\
\hline E5 & 57.80 & 0.61 & 5.12 & 0.01 & 3.14 & 23.75 & 27.14 & 28.10 & 30.40 & 13.32 \\
\hline E6 & 15.39 & 12.47 & 24.93 & 0.21 & 3.14 & 15.17 & 1.87 & 0.13 & 3.16 & 0.80 \\
\hline E7 & 17.21 & 0.61 & 17.28 & 0.11 & 3.14 & 15.17 & 0.40 & 2.58 & 19.96 & 9.43 \\
\hline E8 & 3.46 & 32.28 & 2.04 & 0.01 & 24.53 & 4.78 & 0.28 & 0.13 & 0.05 & 9.91 \\
\hline E9 & 4.86 & 0.77 & 2.04 & 0.00 & 3.14 & 5.65 & 7.71 & 0.13 & 20.94 & 9.99 \\
\hline E10 & 3.52 & 0.77 & 0.82 & 0.03 & 5.24 & 0.68 & 0.88 & 22.24 & 3.17 & 6.48 \\
\hline E11 & 12.90 & 26.15 & 20.10 & 0.02 & 18.42 & 6.49 & 0.94 & 0.13 & 12.28 & 6.26 \\
\hline E12 & 3.34 & 4.19 & 23.21 & 23.56 & 6.74 & 20.39 & 3.49 & 0.13 & 23.95 & 0.83 \\
\hline MAPE & 11.76 & 6.69 & 8.52 & 2.01 & 11.12 & 10.56 & 8.37 & 8.96 & 11.48 & 7.15 \\
\hline
\end{tabular}

Table 4: Results of ten-fold validation. 


\begin{tabular}{|c|c|c|c|}
\hline Fold no. & ANN & NLSF & MLR \\
\hline 1 & 11.76 & 10.68 & 9.52 \\
\hline 2 & 6.69 & 7.67 & 10.20 \\
\hline 3 & 8.52 & 8.14 & 5.36 \\
\hline 4 & 2.01 & 6.65 & 6.95 \\
\hline 5 & 11.12 & 17.22 & 13.20 \\
\hline 6 & 10.56 & 13.24 & 7.08 \\
\hline 7 & 8.37 & 14.89 & 7.51 \\
\hline 8 & 8.96 & 9.87 & 8.19 \\
\hline 9 & 11.48 & 15.21 & 6.98 \\
\hline 10 & 7.15 & 11.17 & 15.07 \\
\hline Average & 8.66 & 11.48 & 9.01 \\
\hline MIN & 2.01 & 6.65 & 5.36 \\
\hline MAX & 11.76 & 17.22 & 15.07 \\
\hline VOE & 8.64 & 12.66 & 9.37 \\
\hline
\end{tabular}

Table 5: Results of MAPE ANN, MLR and NLSF.

\begin{tabular}{|c|c|c|c|c|}
\hline Inputs & All inputs & Human Capital removed & Relational Capital removed & Structural Capital removed \\
\hline MSE & 0.2 & 0.27 & 0.28 & 0.22 \\
\hline Change amount & - & 0.07 & 0.08 & 0.02 \\
\hline Priority & - & 2 & 1 & 3 \\
\hline Relative Importance & - & 0.42 & 0.48 & 0.1 \\
\hline
\end{tabular}

Table 6: The determinants prioritization.

ANN is flexible and has many options that change data to improve result, such as hidden layer, number of neurons, transfer function and etc. Moreover, in input layer the mean of data could have used easily. But in MLR because of large number of variables, the software can't compute interactions in short processing time; therefore it estimates $\mathrm{Y}$ by only linear function of predictors. To solve this problem the mean value of indicators is used and three sub-capitals are classified. Wong et al. says using mean value means all statements (indicators) are assumed to be similarly weighted and it's not a good usage of all predictors [53].

Also in NLSF finding fit function with 23 variables is a time consuming job. Since in the NLSF method, nonlinear function and coefficient must be found with trial-error method, and the result strongly depends on assumed coefficient (Start point), this method is not reliable and not recommended for these types of data and problems. On the other hand MLR doesn't consider nonlinear effect of variables. The advantage of ANN with such architecture is that the sigmoid layer can learn the non-linear relationships between predictors and results, and there is no restraint to set the start point for links weight between neurons. Table 5 presents the result of the mean absolute percentage error (MAPE) of ANN, MLR and NLFS.

\section{ANN and computation of RI of input variables}

Relative importance of inputs to each output have been computed in various researches using ANN approach [53,54]. Sung have studied two method of prioritizing inputs toward one output; the sensitivity analysis and change of mean square error (MSE). He stated that both of them have same results.

Garson and Yoon proposed another method that is dependent on their various strategies of merging and normalizing the correlation weights of the ANN. Wong et al. [53] in their research have stated that Howes and Crook criticized Garson's method for ignoring impact of the bias, that could cause a substantial omission; while Yoon's technique might cause weight cancellation. Therefore, the Change of MSE used as a good technique to compute relative importance between main components of IC.
The change of MSE method is a method to prioritize inputs or factors of one output. The main concept of change of MSE method is measuring changes in MSE after omitting one input from layer of ANN. The single output mean square error of an ANN is calculated by:

$$
M S E=\sum_{i=1}^{k} \frac{\left(O_{i}-P_{i}\right)^{2}}{K}
$$

In this eqn. 8 Oi is Observed Value and $\mathrm{Pi}$ is Predicted value by ANN of output among its validation data set. $\mathrm{K}$ is the number of test samples that are 12 in this research sample. For implementation of Change of MSE method, ANN should be train with $\mathrm{N}_{1}$ input. As mentioned before indicators of IC are used for training ANN, thus all indicators related to one determinant must be removed and change of MSE be recalculated. So respectively indicators of human capital, relational capital and structural capital are removed, and change of MSE is computed. To calculate relative importance of determinants, the changed resulted should be dived by the total change caused by all determinants. For example, RI of Human capital is equal $0.07 /$ $(0.07+0.08+0.02)=0.42$. The determinant prioritization using this method is shown in Table 6 .

\section{Analytical hierarchy process (AHP)}

However, this study assessed accuracy of ANN with MLR and NLFS, it cannot be reliable without benchmarking with the human views of experts. For this aim 12 questionnaires were distributed between experts that have master degree or over 10 years experiment in banking management system.

AHP approach, proposed by Saaty [55] on Wharton Business School, is a pair-wise comparison methodology. AHP results in decomposing a complicated problem and incorporate the solutions. It has been extensively accepted that the AHP evaluations is among the best methodologies to prioritize different indicators $[55,56]$. This is because AHP evaluates the relative importance among quantifiable and qualitative criteria and progressed after a while into a significant strategy in dealing with multi-criteria decision-making problems 
(a)

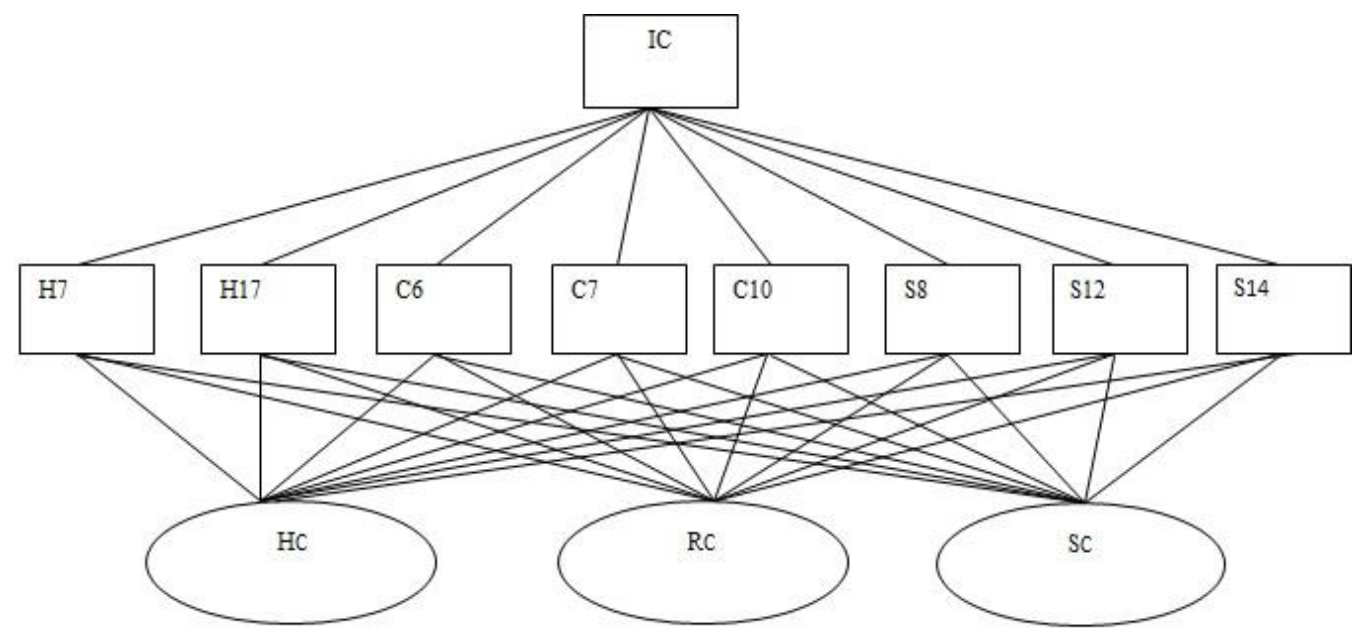

Figure 4: The proposed model hierarchical structure.

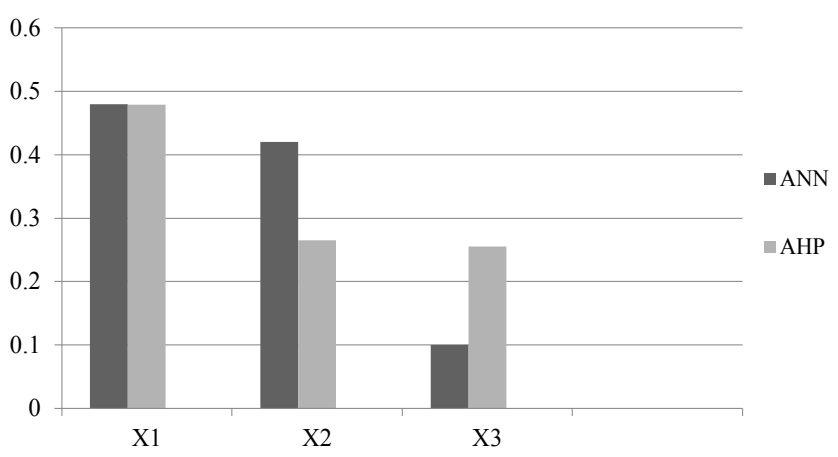

Figure 5: ANN and AHP comparison.

of prioritization and selection [57]. Further, the AHP approach just requires a restricted amount of respondents along with expertise and knowledge; since this approach is principally applied for complicated problems [58]. Several researches were done with AHP for IC indicators or determinants prioritization. Kim and Kumar [19] proposed a framework for prioritization of IC indicators in R\&D using Delphi and AHP approaches. Another research performed in public libraries in Greek, used AHP approach to recognize rank of IC determinants [59]. Uzoka and Ijatuyi [60] used AHP in library management applications in the acquisition process taking into account criteria such as the cost, the availability of resources and the number of copies required. Hsieh et al. [61] also used AHP method for prioritizing performance indicators, in order to create a model assessing the effectiveness of academic libraries in Taiwan. This method can be utilized to assess intangibles, due to the possibility to evaluate quantitative and qualitative. Furthermore, IC components have no scale of measurement, but can be quantified through relative importance [62].

Although Saaty says that his model accepts an unlimited number of entries at the Criteria and Sub criteria levels, he states clearly that only a limited number of analyzed criteria and alternatives can assure an appropriate precision of obtained results. Saaty defines this number as $7+/-2$ (which means 9 maximum) [63]. At the same time, he does not propose any methods of reduction of criteria amount [64]. For overcome this main limitation, in proposed research the criteria were reduced using factor analysis. In the proposed study, The AHP consists of three basic stages, as listed below:

Structuring a hierarchy: Figure 4 illustrates the proposed model hierarchical structure, composed of three levels;

a) Top level (IC as objective);

b) Middle level (the eight IC indicators with factor loading higher than 0.55); and

c) Lowest level (IC determinants: Structural Capital, Customer Capital, and Human Capital).

Obtaining pair-wise comparison: Via a questionnaire that was given to expert their judgments gathered and reformed to pair-wise comparisons. Pair-wise comparisons were considered for alternatives within lowest level with respect to each criteria and another pair-wise comparison for criteria with respect to goal (IC).

All questions and sub indicators were well described to experts so that their judgment is realistic and reliable. For making comparisons, experts were used numerical scale (1-9) [63].

Expert choice analysis: Eight questionnaires among 12 distributed questionnaires were well filled and usable. Next, the Expert Choice software version 11 is used to combine all judgments to rank three IC determinants. Saaty suggests a range of consistency (i.e., $\mathrm{CI}<0.1$ ) to be tolerable [65]. The total inconsistency rate equals to 0.06 that is under 0.1 means judgments are reliable. The judgments are synthesized into the global judgment that leads to achieve final ranking of sub capitals with their relative importance. The prioritization results of ANN and AHP are shown in Figure 5. It is obvious that ANN ranking is similar with AHP except for $\mathrm{X}_{3}$ (structural capital) however the sequence of significance is same.

\section{Conclusions}

In this study, an ANN based method is used for quantifying the relative importance of IC components. The framework of research was practical, reliable, and consistent with previous studies. Confirmatory Factor Analysis was performed to identify more important Indicators in this case study. 23 indicators through 53 were selected as more important ones. Then the framework is designed for evaluation of IC in Mellat Bank of Iran. 
Citation: Shad MS, Nedjati A, Shafiei M (2017) Relative Importance of Intellectual Capital Determinants, Using an Artificial Neural Network Approach: Case Study - Mellat Bank of Iran. J Bus Fin Aff 6: 285. doi: 10.4172/2167-0234.1000285

Page 8 of 9

Based on this framework, ANN model was developed. The ANN with lowest MAPE and SD, and highest R picked for rest of operations. ANN type two with neuron "3", has lowest MAPE and SD, and highest R. After that ANN was retrained to find best test and train data set with respect to minimum MAPE, over tenfold validation. ANN with MAPE "2.01" was best in prediction of Actual values of IC. From results accuracy of ANN in comparison with MLR and NLSF were the best. The minimum and maximum of MAPE for ANN is 2.01, whereas for MLR and NLFS are 9.01 and 11.48, respectively. Variance of error for ANN is, 8.64, whereas for MLR are 9.37 and 12.66 respectively. MLR doesn't consider nonlinear connections between indicators, thus only find linear function of variables. NLSF is sensitive and its response depends on chosen nonlinear function and start points. So ANN technique is more flexible, powerful and intelligent.

After Ensuring of ANN performance, it used to compute Relative importance among 3 sub-capitals of IC. Change of MSE method was used for prioritizing sub-capitals. The results show the most important sub-capital is relational capital; second one is human capital and the third is structural capital.

For more assurance, the results should compare with expert idea about IC. The number of Alternatives for pair-wise comparison should be $7+/-2$. Again indicators with factor loading more than 0.55 were selected and 8 indicators are remained for AHP process. The pairwise comparisons are synthesized with Expert choice 11, by collected data through 8 experts in bank management system. Consequent of synthesized judgments, confirmed ANN technique result. Therefore, the proposed method would be an alternative for subjective judgment of experts.

After all, some advices according to research findings and consuls with experts are given. With respect to resulted prioritization, customer capital level in Mellat Bank of Iran is higher than the others. It shows the powerful competence advantage of system and needs to be diligent to maintain it. But IC is outcome of all three sub-capitals. Therefore, Structural capital that has the lowest relative importance should be improved until leads to more improvement of IC. Next scope that needs improvement is Human capital.

Some limitations of our study are that we have not considered all the population and response of experts are assumed to be equally weighted. The ANN and AHP Fuzzy can be used in future researches. To quantify relative importance of IC determinants, the other methods (except our method) as mentioned previously, is suggested. The result can be compared with this research. Ranking indicators under each determinant can complete our research.

\section{References}

1. Petty R, Guthrie J (2000) Intellectual capital literature review: Measurement, reporting and management. Journal of Intellectual Capital 1: 155-176.

2. Drucker PF, Peter F (1993) Innovation and entrepreneurship: practice and principles. Harper Business.

3. Bontis, N, Crossan M, Hul J, Edvinsson L, Previous TS (1998) Intellectual capital: an exploratory study that develops measures and models. Management Decision 36: 63-76.

4. Barney J (1991) Firm Resources and Sustained Competitive Advantage Journal of Management 17: 99-120.

5. Drucker PF (1985) Innovation and entrepreneurship: practice and principles Harper \& Row

6. Prahalad CK, Hamel G (1990) The Core Competence of the Corporation.
7. Choo CW, Bontis N (2002) The Strategic Management of Intellectual Capita and Organizational Knowledge.

8. Brennan N, Connell B (2000) Intellectual capital: current issues and policy implications. Journal of Intellectual Capital 1: 206-240.

9. Tobin J, Brainard WC (1976) Asset Markets and the Cost of Capital. Cowles Foundation Discussion Papers.

10. Leliaert PJC, Candries W, Tilmans R (2011) Identifying and managing IC: A new classification.

11. Edvinsson L (1997) Intellectual Capital: Realizing Your Company's True Value by Finding Its Hidden Brainpower. HarperCollins.

12. Brooking A (1997) Intellectual capital: [core asset for the third millennium enterprise]. International Thomson Business Press; ITP International Thomson Pub, London.

13. Bontis N (2002) Rising star of the chief knowledge officer. Ivey Business Journal.

14. Leandro C, Paloma S (2002) La Gestión Y Difusión De Información Sobre Intangibles (Informe Sobre Capital Intelectual).

15. Bozbura F, Beskese A, Kahraman C (2007) Prioritization of human capita measurement indicators using fuzzy AHP. Expert Systems with Applications 32: $1100-1112$.

16. Calabrese A, Costa R, Menichini T (2013) Expert Systems with Applications Using Fuzzy AHP to manage Intellectual Capital assets: An application to the ICT service industry. Expert Systems with Applications 40: 3747-3755.

17. Chen H (2009) Measuring intellectual capital using fuzzy analytic hierarchy process 6: 51-61.

18. Han D, Han I (2004) Prioritization and selection of intellectual capita measurement indicators using analytic hierarchy process for the mobile telecommunications industry. 26:519-527.

19. Kim D, Kumar V (2009) A framework for prioritization of intellectual capital indicators in R \& D 10: 277-293.

20. Lee S (2010) Expert Systems with Applications Using fuzzy AHP to develop intellectual capital evaluation model for assessing their performance contribution in a university. Expert Systems with Applications 37: 4941-4947.

21. Sirikrai SB, Tang JCS (2006) Industrial competitiveness analysis: Using the analytic hierarchy process. The Journal of High Technology Management Research 17: 71-83.

22. Mehralian G, Reza H, Akhavan P, Rajabzadeh A (2013) Prioritization of intellectual capital indicators in knowledge-based industries: Evidence from pharmaceutical industry. International Journal of Information Management 33 209-216.

23. Bontis N, keow WCC, Richardson S (2000) Intellectual Capital and Business Performance in Malaysian Industry.

24. Bontis N (2001) Assessing knowledge assets: A review of the models used to measure intellectual capital. International Journal of Management Reviews 3 : 41-60.

25. Kaplan RS, Norton DP (1992) The balanced scorecard--measures that drive performance. Harvard Business Review 70: 71-79.

26. Meritum Project (2002) Guidelines for Managing and Reporting on Intangibles (Intellectual Capital Report). Vodafore Foundation, pp: 1-31.

27. Stewart TA (1997) Intellectual Capital: The New Wealth of Organizations.

28. Sveiby KE (1997) The New Organizational Wealth: Managing \& Measuring Knowledge-based Assets.

29. Kim TT, Kim WG, Park SSS, Lee G, Jee B (2012) Intellectual Capital and Business Performance: What Structural Relationships Do They Have in UpperUpscale Hotels? International Journal of Tourism Research 14: 391-408.

30. Sydler R, Haefliger S, Pruksa R (2014) Measuring intellectual capital with financial figures: Can we predict firm profitability? European Management Journal 32: 244-259.

31. Yang CC Lin CYY (2009) Does intellectual capital mediate the relationship between HRM and organizational performance? Perspective of a healthcare industry in Taiwan. The International Journal of Human Resource Management 20: $1965-1984$. 
Citation: Shad MS, Nedjati A, Shafiei M (2017) Relative Importance of Intellectual Capital Determinants, Using an Artificial Neural Network Approach: Case Study - Mellat Bank of Iran. J Bus Fin Aff 6: 285. doi: 10.4172/2167-0234.1000285

32. Marr B, Gray D, Neely A (2003) Why do firms measure their intellectual capital? 4: 441-464.

33. Roos G, Roos J (1997) Measuring your Company's Intellectual Performance. Long Range Planning, Special Issue on Intellectual Capital.

34. Cohen S, Kaimenakis N (2007) Intellectual Capital and Corporate Performance in Knowledge-Intensive SMEs.

35. Bontis N (1999) Managing organizational knowledge by diagnosing intellectual capital: Framing and advancing the state of the field.

36. Roos J (1997) Intellectual capital: Navigating the new business landscape. Macmillan Business.

37. Bontis N (1998) Intellectual capital: an exploratory study that develops measures and models. Management Decision 36: 63-76.

38. Sydler R, Haefliger S, Pruksa R (2013) Measuring intellectual capital with financial figures: Can we predict firm profitability? European Management Journal.

39. Edvinsson L, Sullivan $P$ (1996) Developing a model for managing intellectual capital. European Management Journal 14: 356-364.

40. Roos J, Edvinsson L, Roos G (1998) Intellectual Capital: Navigating in the New Business Landscape.

41. Degroote MG, Bontis N, Keow WCC (2000) Intellectual capital and business performance in Malaysian industries industries. Journal of Intellectual Capital 1: $85-100$.

42. Bontis N (2003) Intellectual Capital Disclosure in Canadian Corporations. Journal of Human Resource Costing \& Accounting 7: 9-20.

43. Calvo CL, Chaminade C, García-Ayuso CM, Sánchez MMP (2004) Directrices para la gestión y difusión de la información sobre intangibles (informe de capital intelectual).

44. Bozbura FT (2004) Emerald Article: Measurement and application of intellectual capital in Measurement and application of intellectual capital in Turkey.

45. Engström TEJ, Westnes $P$, Westnes SF (2003) Evaluating intellectual capital in the hotel industry. Journal of Intellectual Capital 4: 287-303.

46. Becker BE, Huselid MA, Ulrich D (2001) The HR scorecard: linking people, strategy, and performance. Harvard Business School Press.

47. Bontis N (2012) Measures and models Intellectual capital: An exploratory study that develops measures and models.

48. Haykin SS (2009) Neural Networks and Learning Machines.

49. Bishop CM (1995) Neural networks for pattern recognition. Clarendon Press.
50. Deng WJ, Pei W (2009) Fuzzy neural based importance-performance analysis for determining critical service attributes. Expert Systems with Applications 36: 3774-3784.

51. Deng W, Chen W, Pei W (2008) Back-propagation neural network based importance-performance analysis for determining critical service attributes. Expert Systems with Applications 34: 1115-1125.

52. Huang Z, Chen H, Hsu CJ, Chen WH, Wu S (2004) Credit rating analysis with support vector machines and neural networks: a market comparative study. Decision Support Systems 37: 543-558.

53. Wong TC, Wong SY, Chin KS (2011) A neural network-based approach of quantifying relative importance among various determinants toward organizational innovation. Expert Systems with Applications 38: 13064-13072.

54. Olden JD, Jackson DA (2002) Illuminating the "black box": a randomization approach for understanding variable contributions in artificial neural networks. Ecological Modelling 154: 135-150.

55. Saaty TL (1986) Axiomatic Foundation of the Analytic Hierarchy Process. Management Science 32: 841-855.

56. Melo LB, Sampaio IC (2006) Quality Measures for Libraries and Information.

57. Ishizaka A, Lusti M (2006) How to derive priorities in AHP: a comparative study. Central European Journal of Operations Research 14: 387-400.

58. Takala J, Suwansaranyu U, Phusavat K (2006) A proposed white-collar workforce performance measurement framework. Industrial Management \& Data Systems 106: 644-662.

59. Asonitis S, Kostagiolas PA (2010) An analytic hierarchy approach for intellectual capital Evidence for the Greek central public libraries 31: 145-161.

60. Uzoka FME, ljatuyi O (2005) Decision support system for library acquisitions: A framework. The Electronic Library 23: 453-462.

61. Hsieh LF, Chin JB, Wu MC (2006) Performance evaluation for university electronic libraries in Taiwan. The Electronic Library 24: 212-224.

62. Grimaldi M, Rippa P (2011) An AHP-based framework for selecting knowledge management tools to sustain innovation process. Knowledge and Process Management 18: 45-55.

63. Saaty TL (2003) Rank, normalization and idealization in the analytic hierarchy process. $7^{\text {th }}$ ISAHP proceedings pp: 57-64.

64. Gawlik R (2008) Preliminary Criteria Reduction for the Application of Analytic Hierarchy Process Method. MPRA Paper.

65. Saaty TL (1980) The Analytic Hierarchy Process: Planning, Priority Setting, Resource Allocation. 